\title{
Research Paper: Comparative Assessment of Speech Perception, Phonological Information Processing, and Syntactic Skills in Normal and Dyslexic Children of Second and Third Grade
}

Sajad Ganjkhanlu $^{1}$ (D, Zahra Soleymani ${ }^{1^{*}}$ (D), Mandana Nourbakhsh², Mina Mohammadi Nouri

1. Department of Speech Therapy, School of Rehabilitation, Tehran University of Medical Sciences, Tehran, Iran.

2. Department of Linguistics, Al-Zahra University, Tehran, Iran.

3. Department of Mathematics, Statistics and Computer Science, Faculty of Science, Tehran University, Tehran, Iran.

\begin{tabular}{|l|l|l|l}
\hline $\begin{array}{l}\text { Use yourdevice to san } \\
\text { and read the article online }\end{array}$ & $\begin{array}{l}\text { Crtation: Ganjkhanlu S, Soleymani Z, Nourbakhsh M, Mohammadi Nouri M. Comparative Assessment of Speech Percep- } \\
\text { tion, Phonological Information Processing and Syntactic Skills in Normal and Dyslexic Children of the Second and Third Grade. } \\
\text { Journal of Modern Rehabilitation. 2019; 13(2):105-112. http://dx.doi.org/10.32598/JMR.13.2.105 }\end{array}$ \\
dol'http://dx.doi.org/10.32598/JMR.13.2.105
\end{tabular}

\section{(1) (3)}

Article info:

Received: 10 Sep 2018

Accepted: 27 Jan 2019

Available Online: 01 Apr 2019

\section{Keywords:}

Speech perception, Dyslexia, Nonword repetition, Sentence comprehension

\section{A B STRACT}

Introduction: Many studies have claimed that speech perception in dyslexic children is impaired in comparison to normal children in a way that dyslexic children are weaker in the discrimination and identification of phonemes. In this research, we study speech perception, syntactic skills, and phonological processing in the normal and dyslexic Farsi-speaking children.

Materials and Methods: We examined the speech perception in 30 normal and 18 dyslexic children, using speech identification task in 3 continua of Voice Onset Time (VOT) in [ba-pa], [da-ta], and [ga-ka]. We also studied 2 other skills to examine the processing of phonological information and syntactic skills. We used the nonword repetition test and passive sentence comprehension, respectively. To compare the data, the Mann-Whitney U test, t-test, and logistic regression were used.

Results: Dyslexic children in speech identification task performed similarly to normal children in all 3 continua $(\mathrm{P}=0.81,0.87$, and 0.58$)$; but, in the nonword repetition test, they were significantly lower than normal children $(\mathrm{P}=0.01)$, and in the passive sentence comprehension task, there was no significant difference between normal and dyslexic children $(\mathrm{P}=0.12)$.

Conclusion: The results of various studies for speech perception and linguistic abilities in dyslexic children are contradictory. They are mostly related to the tasks that have been used. Therefore, more studies in the future are suggested.

* Corresponding Author:

Zahra Soleymani, PhD.

Address: Department of Speech Therapy, School of Rehabilitation, Tehran University of Medical Sciences, Tehran, Iran.

Tel: +98 (912) 2036683

E-mail: soleymaniz@sina.tums.ac.ir 


\section{Introduction}

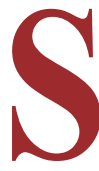

peech perception is called a process, through which perceptual mapping occurs from the acoustic speech signal to a linguistic representation in a person's mind [1] Through studying this phenomenon, one can obtain a comprehensive view of the basic processes of language acquisition; also, knowing the relationship between speech perception and linguistic skills can help predict future linguistic disorders [2]. In fact, during the process of speech perception, phonemes are interpreted and understood, and this process can be in the form of sound, syllables, and words [1]. In this study, our focus is on syllabic speech perception. Reading disorder is one of the most common problems for students and dyslexia is the most important one. Dyslexics often have reading difficulty in their classes because of reading disorders [3]

Dyslexia means the reading ability is lower than in expected age, education, and intelligence of the child. The characteristics of dyslexia are the inability to word recognition, false and slow reading, and poor understanding [4]. One of the main causes of dyslexia is perceptual deficit such as visual and auditory perception. The results of a study also indicated that children with the reading disorder in the index of visual perception and auditory perception acted significantly lower than the normal children [5]. This disorder is a learning disability, in which the fluency and accuracy of reading are affected, and also phonological awareness, phonological decoding, and letter encryption are impaired [6]. Dyslexia is often characterized by difficulties in decoding words, low ability in phonological processing skills, and various problems in the written language [7].

According to the result of studies, the learning of reading significantly correlates with speech perception [8]. Phonological information is often acquired through speech perception; on the other hand, reading and spelling problems are related to the specific deficits in the representation and use of phonological information. Phonological deficit limits the ability of dyslexic children to learn sound-letter matching. It is generally proved that children with similar patterns of reading deficit cannot be assumed to have similar deficits [9].

Although in most cases dyslexic children have normal intelligence, they cannot achieve good academic achievement and they continue to study with great difficulty or leave school, which, in turn, has many social, economic, cultural, and emotional-psychological consequences for them and society [4].
Many studies have investigated the perception of speech in dyslexic children, but the results have not yet reached a general consensus, and in some cases, they are completely contradictory. To resolve these contradictory, we used common clinical tasks in the Farsi language in order to better diagnose normal and dyslexic children.

In the present study, 2 tasks were used for the assessment of phonological information processing and syntactic skills. We wanted to know how speech perception deficits are accompanied by language problems. Considering that in Farsi language there is no research on these issues, the need for such a study becomes more urgent.

Most studies found that nonword repetition is related to dyslexia because it shows the efficiency of phonological information processing and nonword repetition is considered a predictor of word decoding skill [10]. Hence, we studied nonword repetition in Farsi language and its relation with dyslexia.

As the comprehension of the text is related to linguistic skills, in dyslexic children in addition to phonological skills, it is necessary to examine the syntactic and semantic skills. To this aim, we examined the comprehension of Farsi's passive sentences as a proxy for syntactic and semantic processing. Some previous studies found deficiencies in the comprehension of sentences in dyslexic children in comparison to normal age-matched children [11-13] and some studies found that dyslexic children are susceptible to problems in sentence comprehension $[14,15]$.

\section{Materials and Methods}

This is a cross-sectional study that examined speech perception in normal and dyslexic children. The participants included 30 normal children and 18 dyslexic children enrolled in the second and third elementary schools. This study is in accordance with the ethical principles and national norms and standards for conducting medical research in Iran with the approval ID of IR.TUMS. FNM.REC.1397.060 in the institutional research ethics committee.

The inclusion criteria for two groups of children included: 1. Having normal intelligence quotient; 2 . Having no speech disorders notably articulation problems; 3. Having no visual or auditory impairment; 4. Having no cerebral palsy or obvious sensory-motor disorder; 5 . Studying in the second or third basic elementary school; 6. Being monolingual and Farsi speakers; 7. Having no educational deprivation history. 
The parent's questionnaire and the teacher's questionnaire were completed. The parent's questionnaire, in addition to the demographic information of the child, included 7 questions that provided information about the inclusion criteria. The teacher's questionnaire included 7 questions of yes/no completed by a teacher or therapist; if they answered "yes" from 3 questions, it would be determined that the child was at risk of dyslexia. The diagnosis of dyslexic children was confirmed by reading and dyslexia NAMA reading tests. In order to homogenize the two groups, normal and dyslexic children were selected from the same area.

If the inclusion criteria were met, the child could enroll in the study, and if the child did not want to cooperate during the study or there was a problem to perform the tests, he/she would be excluded. The parents completed the form of ethical considerations and signed the consent form. For each subject, NAMA, speech perception, passive sentence comprehension tasks, and nonword repetition tests were examined. In order to reduce the fatigue effect, these tests were performed rotationally and the results were recorded.

The speech perception task is based on the Voice Onset Time (VOT), which means the time interval between the release of a stop consonant and the start of larynx periodic vibration. The Farsi language is in the category of aspiration languages and the VOT has a strong correlation with voicing [16]. We used voicing identification because most of the previous studies used the same task to assess speech perception $[8,9]$.

In speech perception task, 3 voiced syllables ([ba], [da], and [ga]) versus their voiceless pairs ([pa], [ta], and [ka]) were presented auditory and in a random way for the child; then, the child had to repeat the syllable he/she heard and the examiner, according to the child's repetition, chose one of the two syllables displayed on the screen. These stimuli were artificially designed by PRAAT version 5.2.15. For each pair of syllables, 92 stimuli were provided with $5 \mathrm{~ms}$ time interval and the difference in stimuli was in VOT at the onset of the consonant of the syllable, ranging from $-40 \mathrm{~ms}$ to $+70 \mathrm{~ms}$. Finally, the location of the sudden change of responses in the continuum of VOT along with the slope of this change was recorded as the final result.

In order to assess the nonword repetition skill, we used the Farsi nonword repetition test, which has 25 nonwords (for example: /xinu/, /kibzomini/, etc.) and the child received a score for each correct repetition. Also, to assess the understanding of the passive sentences comprehension, the task of Afaghi et al. was used. During this task, 15 passive sentences were told to the child, and the child had to show the associated picture with the sentence and received a score for each correct answer, for example: "Fish was eaten" (in Farsi).

Eventually, SPSS v. 22 was used to analyze the data. To compare the results of the nonword repetition test and the passive sentence's comprehension task between normal and dyslexic children, both parametric independent t-test and non-parametric Mann-Whitney U test were used. To compare the results of the speech perception task, we used the logistic regression. The results are presented in text format, tables, and charts.

\section{Results}

In this study, 48 students were examined. As presented in Table 1, 21 (43.8\%) students were female and 27 (56.2\%) students were male. Twenty-five of the students were studying in the third elementary grade and 23 were studying in the second elementary grade. The mean age of the children was 9 years with a Standard Deviation (SD) of 6 months. The age range was between 8 and 10: 3 (Table 1).

The Mean \pm SD score of NAMA subtests in the dyslexic group (89.9 \pm 3.7$)$ was lower than the normal group (101.6 \pm 4.3$)$ (Table 2). In the nonword repetition test, the Mean \pm SD performance of the dyslexic children

Table 1. Children's distribution based on group and gender

\begin{tabular}{|c|c|c|c|}
\hline \multirow{2}{*}{ Variables } & \multicolumn{2}{|c|}{ Group } & \multirow{2}{*}{ Total } \\
\hline & Normal & Dyslexic & \\
\hline \multirow[b]{2}{*}{ Gender } & 16 & 11 & 27 \\
\hline & 14 & 7 & 21 \\
\hline Total (mean age) & $30(8: 11)$ & $18(9: 1)$ & $48(9: 0)$ \\
\hline
\end{tabular}


Table 2. Basic statistic on NAMA subtests for the normal and dyslexic group

\begin{tabular}{ccc}
\hline Subtests & \multicolumn{2}{c}{ Mean \pm SD } \\
\cline { 2 - 3 } Word reading & Normal & Dyslexic \\
\cline { 2 - 3 } Word chains reading & $97 \pm 6$ & $83 \pm 10$ \\
Rhyming & $99 \pm 7$ & $86 \pm 4$ \\
Picture naming & $97 \pm 7$ & $104 \pm 12$ \\
Text comprehension & $119 \pm 11$ & $89 \pm 14$ \\
Word comprehension & $104 \pm 15$ & $100 \pm 4$ \\
\hline Phoneme reduction & $105 \pm 7$ & $88 \pm 4$ \\
\hline Nonword and pseudo-word reading & $101 \pm 6$ & $80 \pm 8$ \\
\hline Letter fluency & $90 \pm 10$ & $93 \pm 5$ \\
\hline Category fluency & $105 \pm 9$ & $89 \pm 4$ \\
\hline
\end{tabular}

Table 3. Results of the speech identification task

\begin{tabular}{cccccc}
\hline \multirow{2}{*}{ Continuum } & \multicolumn{2}{c}{ Edge of Categories } & \multicolumn{3}{c}{ Slope of Logistic Regression } \\
\cline { 2 - 6 } & Normal & Dyslexic & Normal & Dyslexic & P \\
\hline /ba/-/pa/ & 25.48 & 25.12 & 1.065 & 1.048 & 0.815 \\
\hline$/ \mathrm{da} /-/ \mathrm{ta} /$ & 25.10 & 25.08 & 1.058 & 1.064 & 0.874 \\
\hline$/ \mathrm{ga} /-/ \mathrm{ka} /$ & 24.84 & 23.92 & 1.052 & 1.061 & 0.587 \\
\hline
\end{tabular}

(20.22 \pm 2.43$)$ was significantly lower than the normal children $(22.13 \pm 2.24)(\mathrm{P}=0.010)$. In the passive sentence comprehension task, although the Mean \pm SD score of the dyslexic group (13.83 \pm 0.76$)$ was lower than that of the normal group $(14.37 \pm 1.2)$, this difference was not significant $(\mathrm{P}=0.128)$.

In the speech identification task, as presented in Table 3 , the normal and dyslexic groups performed roughly the same, and the values obtained for the slope of logistic regression and the edge of the categories in the two groups were very close to each other. In none of the 3 continua, there was no significant difference between the two groups; the greatest difference in the slope of logistic regression was in the continuum $/ \mathrm{ga} /-\mathrm{ka} /$ with a significance level of 0.587 .

\section{Discussion}

In the present study, we found dyslexic children performed as normally-developing children in speech perception; however, this result is consistent with some studies $[8,17,18]$. This consistency cannot be seen with others $[19,20]$. Since in this study dyslexic children were not classified into different subgroups, we could not discuss the relationship between speech perception and phonological processing. Some of the studies confirm that speech perception is impaired in dyslexic children, but others do not confirm this claim. The reason for this controversy is that dyslexic children are categorized into subgroups, and some studies have acknowledged the weakness in speech perception in a specific subgroup of dyslexic children [9, 18].

We considered the existence of a battery for the assessment of speech perception as an important reason for the 
different results of studies. In this study, we used only speech identification tasks in plosive consonants. Other tasks can be used in the form of phoneme, syllable, word, and nonword. Some studies, whose results were similar to this study, have used the same tasks in order to assess speech perception $[9,17,19]$, but some others used different tasks [20].

The dyslexic children were significantly weaker than the normal children in the nonword repetition test. Regarding the fact that nonword repetition shows the efficiency of phonological information processing, most researchers find it related to dyslexia and reading difficulties [10]. Although many researchers believe that nonword repetition is the reflection of phonological skills [10], they do not agree with how the nonword repetition is related to phonological skills and dyslexia.

In an approach, it is assumed that nonword repetition shows the function of the verbal short-term memory [21]. The learning of reading is basically related to verbal short-term memory [22, 23]. This type of memoryimpaired in dyslexic children [23]. Other view states that weakness in nonword repetition is a reflection of weakness in oral language skills, and children, who have difficulty in oral language skills, act significantly weaker than normal children in nonword repetition; also, the effect size in nonwords with high wordlikeness was more than those with low wordlikeness [10]. Considering the fact that the nonwords [24] used in this study were built from the actual words of Farsi language, dyslexic children had significant weakness in the scores compared to the normal children.

According to another approach, the deficit of nonword repetition in dyslexic children is justified by the phonological representation [22]. Regarding the point that nonword repetition requires identifying phonemic components and this identification is done by the help of phonemic representations, this view states that dyslexic children act weaker in phonemic representation; thus, they cannot identify the phonemic components of nonword and, finally, encounter problems in nonword repetition.

Almost all studies show that dyslexic children have deficits in nonword repetition [25]. However, there is still disagreement regarding the degree of deficit in nonword repetition skills, as some studies show a small difference between normal and dyslexic children [26], while other studies show significant differences [27]. The main reason for this difference in the results can be found in oral language skills; in dyslexic children, the weaker the oral language skills are, the weaker they act in nonword repetition [10]. Since nonword repetition is considered a predictor of word decoding skills, we can consider it a cognitive marker in dyslexic children [10].

Our purpose was to measure the relationship between speech perception and nonword repetition; but, according to the results of this study, since the speech perception was the same in the normal and dyslexic groups, it cannot be said that speech perception is responsible for deficit in the nonword repetition as a task, which measures phonological processing.

Text processing is a language-based process that depends on a variety of factors that not only includes the phonemes and features but also includes semantic and syntactic domains [28]. On this basis, it is expected that in the study of dyslexia, in addition to phoneme and syllable, syntax and semantics be noted. Therefore, in this research, we consider passive sentence comprehension as an example of a syntactic and semantic processing function. In passive sentence comprehension tasks, although dyslexic children scored less than normal children, this difference is not significant. In explaining this finding, we firstly present two approaches to sentence comprehension.

The first view states that dyslexic children have deficits in some basic syntactic abilities because of the delay in the development of phonologic, morphologic, and syntactic skills [11]. Therefore, dyslexic children can experience problems in different language tasks that involve some kinds of syntactic and semantic skills. Of course, there is a lot of research in this area, some of which believe that dyslexic children have difficulty in complex grammatical skills, while in basic skills, they perform similar to normal children [29].

Another view conveys the weakness in sentence comprehension as a result of working memory limits [30]. Dyslexic children cannot accurately keep all the words of a sentence because of their weakness in working memory; thus, they lose some of the sentence information and, ultimately, encounter problems in the comprehension of the sentence.

In explaining the results of this section of the study, with regard to both views, the reason can be justified by the fact that the passive sentence comprehension task used in this study contains relatively short sentences and the child should choose one of the 3 pictures that are most relevant to the sentence. With respect to the length of the sentence used in this task, it cannot show the weakness of dyslexic children. If we look at the results of the text comprehension 
subtest of NAMA, this subtest for each grade consists of 2 texts with a sentence length of 3 to 8 words followed by 5 to 7 questions for each text. The average score of dyslexic children in the text comprehension subtest is 89.39 and the average of normal children is much higher than that of dyslexic children $(\mathrm{P}=0.001)$; the reason for this difference can be interpreted that this subtest has a syntactically high complexity that can show the weakness of dyslexic children. On the other hand, because of having a longer length, it also involves working memory so that dyslexic children cannot function as normal children.

One of the limitations we encountered in this study was the lack of dyslexia diagnostic tests in the Farsi language to categorize dyslexic children into subgroups, as well as the lack of similar studies in the Farsi language that limits the explanation of theoretical issues in the Farsi language. Another limitation refers to the limited sample size because of the lack of cooperation of relevant institutions in accessing more samples. Finally, the sampling area was limited only to Tehran.

It is suggested to develop and standardize an accurate diagnostic test for dyslexia and a comprehensive test in relation to speech perception in the Farsi language. Conducting research on the speech perception in the Farsi-speaking dyslexic children with high sample size and accurate tests in the subgroups of dyslexia, as well as carrying out studies on the relationship between the aspects of speech perception and impaired functions of dyslexic children are highly suggested.

Dyslexic children are weaker than normal children in the nonword repetition test, but they performed the speech perception and passive sentence comprehension tasks similar to their normal age-matched peers.

\section{Ethical Considerations}

\section{Compliance with ethical guidelines}

This study was approved by the Ethics Committee of Tehran University of Medical Sciences (Code: IR.TUMS.FNM. REC.1397.060). Before any testing, the written informed consent was received from the children's parents or teachers.

\section{Funding}

This research did not receive any specific grant from funding agencies in the public, commercial, or not-forprofit sectors.

\section{Authors contributions}

Conceptualization, investigation: Zahra Soleymani, Sajad Ganjkhanlu; Methodology: All authors; Writing-original draft: Sajad Ganjkhanlu; Writing-review \& editing: Zahra Soleymani, Mandana Nourbakhsh, Mina Mohammadi Nouri.

\section{Conflict of interest}

The authors declared no conflict of interest.

\section{Acknowledgements}

We would like to thank Sharif learning-disability school, Yousef-Abad and Fereshteh speech therapy clinic, Navid-Asr rehabilitation clinic, Behbud rehabilitation center, Bahmani speech therapy clinic, and Aftab psychology for providing students.

\section{References}

[1] Holt LL, Lotto AJ. Speech perception as categorization. Attention, Perception, \& Psychophysics. 2010; 72(5):1218-27. [DOI:10.3758/APP.72.5.1218] [PMID] [PMCID]

[2] Ziegler JC, Pech-Georgel C, George F, Alario FX, Lorenzi C. Deficits in speech perception predict language learning impairment. Proceedings of the National Academy of Sciences of the United States of America. 2005; 102(39):14110-5. [DOI:10.1073/pnas.0504446102] [PMID] [PMCID]

[3] Anastasi A, Urbina S. Psychological testing. $7^{\text {th }}$ ed. N.J.: Upper Saddle River: Prentice Hall/Pearson Education; 1997.

[4] American Psychiatric Association. Task Force on Nomenclature and Statistics, American Psychiatric Association. Committee on Nomenclature and Statistics, American Psychiatric Association. Work Group to Revise DSM-III. Diagnostic and statistical manual of mental disorders. Philadelphia: American Psychiatric Association; 1980.

[5] Howes NL, Bigler ED, Burlingame GM, Lawson JS. Memory performance of children with dyslexia: A comparative analysis of theoretical perspectives. Journal of Learning Disabilities. 2003; 36(3):230-46. [DOI:10.1177/002221940303600303] [PMID]

[6] Berninger VW, Abbott RD, Lee Swanson H, Lovitt D, Trivedi P, Lin SJ, et al. Relationship of word-and sentence-level working memory to reading and writing in second, fourth, and sixth grade. Language, Speech, and Hearing Services in Schools. 2010; 41(2):179-93. [DOI:10.1044/0161-1461(2009/08-0002)]

[7] Tønnessen, FE. How can we best define 'dyslexia'? Dyslexia. 1997; 39(2):139-56

[8] Godfrey JJ, Syrdal-Lasky K, Millay KK, Knox CM. Performance of dyslexic children on speech perception tests. Journal of Experimental Child Psychology. 1981; 32(3):401-24 [DOI:10.1016/0022-0965(81)90105-3] 
[9] Joanisse MF, Manis FR, Keating P, Seidenberg MS. Language deficits in dyslexic children: Speech perception, phonology, and morphology. Journal of Experimental Child Psychology. 2000; 77(1):30-60. [DOI:10.1006/jecp.1999.2553] [PMID]

[10] Melby-Lervåg M, Lervåg A. Oral language skills moderate nonword repetition skills in children with dyslexia: A metaanalysis of the role of nonword repetition skills in dyslexia. Scientific Studies of Reading. 2012; 16(1):1-34. [DOI:10.1080/1 0888438.2010.537715]

[11] Byrne B. Deficient syntactic control in poor readers: Is a weak phonetic memory code responsible? Applied Psycholinguistics. 1981; 2(3):201-12. [DOI:10.1017/S0142716400006512]

[12] Leikin M, Bouskila OA. Expression of syntactic complexity in sentence comprehension: A comparison between dyslexic and regular readers. Reading and Writing. 2004; 17(7-8):801-22. [DOI:10.1007/s11145-004-2661-1]

[13] Fletcher JM, Satz P, Scholes RJ. Developmental changes in the linguistic performance correlates of reading achievement. Brain and Language. 1981; 13(1):78-90. [DOI:10.1016/0093934X(81)90130-9]

[14] Bishop DV, Snowling MJ. Developmental dyslexia and specific language impairment: Same or different? Psychological Bulletin. 2004; 130(6):858-86. [DOI:10.1037/00332909.130.6.858] [PMID]

[15] Robertson EK, Joanisse MF. Spoken sentence comprehension in children with dyslexia and language impairment: The roles of syntax and working memory. Applied Psycholinguistics. 2010; 31(1):141-65. [DOI:10.1017/S0142716409990208]

[16] Bijankhan M, Nourbakhsh M. Voice onset time in Persian initial and intervocalic stop production. Journal of the International Phonetic Association. 2009; 39(3):335-64. [DOI:10.1017/ S0025100309990168]

[17] Ziegler JC, Pech-Georgel C, George F, Lorenzi C Speech-perception-in-noise deficits in dyslexia. Developmental Science. 2009; 12(5):732-45. [DOI:10.1111/j.14677687.2009.00817.x] [PMID]

[18] Manis FR, McBride-Chang C, Seidenberg MS, Keating P, Doi LM, Munson B, et al. Are speech perception deficits associated with developmental dyslexia? Journal of Experimental Child Psychology. 1997; 66(2):211-35. [DOI:10.1006/ jecp.1997.2383] [PMID]

[19] Cabbage KL, Hogan TP, Carrell TD. Speech perception differences in children with dyslexia and persistent speech delay. Speech Communication. 2016; 82:14-25. [DOI:10.1016/j. specom.2016.05.002]

[20] Bogliotti C, Serniclaes W, Messaoud-Galusi S, SprengerCharolles L. Discrimination of speech sounds by children with dyslexia: Comparisons with chronological age and reading level controls. Journal of Experimental Child Psychology. 2008; 101(2):137-55. [DOI:10.1016/j.jecp.2008.03.006] [PMID]

[21] Gathercole SE. Nonword repetition and word learning: The nature of the relationship. Applied Psycholinguistics. 2006; 27(4):513-43. [DOI:10.1017/S0142716406060383]

[22] Wagner RK, Torgesen JK. The nature of phonological processing and its causal role in the acquisition of reading skills. Psychological Bulletin. 1987; 101(2):192-212. [DOI:10.1037/0033-2909.101.2.192]
[23] Gathercole SE, Baddeley AD. Working memory and language. New York: Psychology Press; 2014.

[24] Soleymani Z, Amidfar M, Dadgar H, Jalaie S. Working memory in Farsi-speaking children with normal development and cochlear implant. International Journal of Pediatric Otorhinolaryngology. 2014; 78(4):674-8. [DOI:10.1016/j. ijporl.2014.01.035] [PMID]

[25] Gerry Taylor H, Lean D, Schwartz S. Pseudoword repetition ability in learning-disabled children. Applied Psycholinguistics. 1989; 10(2):203-19. [DOI:10.1017/S0142716400008523]

[26] Landerl K. Word recognition deficits in German: More evidence from a representative sample. Dyslexia. 2001; 7(4):183-96. [DOI:10.1002/dys.199] [PMID]

[27] Marshall CM, Snowling MJ, Bailey PJ. Rapid auditory processing and phonological ability in normal readers and readers with dyslexia. Journal of Speech, Language, and Hearing Research. 2001; 44(4):925-40. [DOI:10.1044/10924388(2001/073)]

[28] Ferstl E., d'Arcais GF. The reading of words and sentences. In: Friederici AD. Language Comprehension: A Biological Perspective. Berlin, Heidelberg: Springer; 1999. [DOI:10.1007/978-3-642-59967-5_6]

[29] Deutsch A, Bentin S. Attention factors mediating syntactic deficiency in reading-disabled children. Journal of Experimental Child Psychology. 1996; 63(2):386-415. [DOI:10.1006/ jecp.1996.0055] [PMID]

[30] Perfetti CA, Lesgold AM. Discourse comprehension and sources of individual differences. Washington, D.C.: ERIC Clearinghouse; 1977. 
This Page Intentionally Left Blank 